\title{
Böbrek Nakli Alıcılarında İnsizyonel Herni: Tek Merkez Deneyimi
}

\section{Incisional Hernia in Kidney Transplant Recipients: A Single Center Experience}

\author{
Gökhan Ertuğrul ${ }^{1}$, Tumay Yanaral ${ }^{2}$ \\ ${ }^{1}$ Medipol Üniversitesi Tıp Fakültesi Organ Nakli Merkezi, İstanbul, Türkiye. \\ ${ }^{2}$ Medipol Üniversitesi Tıp Fakültesi Anesteziyoloji ve Reanimasyon Anabilim Dalı, İstanbul, Türkiye \\ e-posta: mdgertugrul@gmail.com,uludagt@yahoo.com \\ Orcid: 0000-0002-8351-4220 \\ Orcid: 0000-0003-3917-8183 \\ *Sorumlu yazar/Corresponding author: Gökhan Ertuğrul ${ }^{1}$ \\ Gönderim tarihi/Received:16.02.2020 \\ Kabul tarihi/Accepted:01.06.2020 \\ DOI:10.34087/cbusbed.689854
}

Giriș ve Amaç: İnsizyonel herni, hastaların yaşam kalitesini olumsuz etkileyebilecek ciddi bir komplikasyon olup tüm ameliyatlardan sonra görülebilir. İnsidansı, böbrek naklinden sonra \% 1 ile 5 arasındadır. Bu retrospektif çalışmanın amacı, böbrek nakli sonrası alıcı hastalarda gelişen insizyonel hernilerin değerlendirilmesidir.

Gereç ve Yöntemler: Nisan 2014- Nisan 2019 tarihleri arasında İstanbul Medipol Üniversitesi Tıp Fakültesi Hastanesi Organ Nakli Bölümü'nde, böbrek nakli yapılan 150 hasta retrospektif olarak incelendi. İnsizyonel herni 7 $(\% 4,7)$ hastada saptandı. Bu hastaların demografik ve klinik özellikleri, predispozan faktörleri ve cerrahi sonuçları değerlendirildi.

Bulgular: Böbrek nakli sonrası insizyonel herni saptanan hastaların yaş ortalaması $61 \pm 3,2$ yıldı. Bu hastaların 5 'i $(\% 71,4)$ erkekti. Hastaların ortalama Vücut Kitle İndeksi (VKI) 34,8 $\pm 2,1$ kilogram/ metrekare (kg/m2) idi. Hastalardan 5'inde $(\% 71,4)$ Diabetus Mellitus vard1. Hastalardan 5'inde $(\% 71,4)$ yara yeri enfeksiyonu mevcuttu. Tüm hastalar prolene mesh greft ile onarıldı (açık-onlay tekniği ile). Otuz dokuz (14-60) aylık takipte komplikasyon ve nüks görülmedi.

Sonuç: Risk grubunda yaşlı, obez, diyabetik ve ameliyat sonrası yara yeri infeksiyonu gelişen hastalar vardı. Böbrek nakli sonrası gelişen insizyonel hernilerin erken tanı ve tedavisi için özellikle bu hasta gruplarına dikkat edilmesi gerektiğini düşünüyoruz.

Anahtar Kelimeler: Analiz, böbrek nakli, insizyonel herni

\begin{abstract}
Objective: An incisional hernia is a serious complication that can negatively affect patients quality of life and can be seen after all operations. Its incidence is between 1 and 5\% after kidney transplantation. The aim of this retrospective study has been to evaluate the incisional hernias developing in recipient patients after kidney transplantation.

Materials and Methods: Between April 2014 and April 2019, 150 patients who underwent kidney transplantation at Istanbul Medipol University Medical Faculty Organ Transplant Department were retrospectively analyzed. The incisional hernia was detected in $7(4.7 \%)$ patients. Demographic and clinical features, predisposing factors and surgical results of these patients were evaluated.

Results: The mean age of patients with an incisional hernia after kidney transplantation was $61 \pm 3.2$ years. Five of these patients (71.4\%) were male. The mean Body Mass Index (BMI) of the patients was $34.8 \pm 2.1$ kilograms / square meter $\left(\mathrm{kg} / \mathrm{m}^{2}\right)$. Diabetes Mellitus was present in 5 patients $(71.4 \%)$. Wound infection was present in 5 (71.4\%). All patients were repaired with a prolene mesh graft (open onlay technique). No complication and recurrence was observed in the thirty-nine (14-60) months follow-up.

Conclusions: There were elderly, obese, diabetic and postoperative wound infection patients in the risk group. We think, attention must be paid especially in these patient groups for the early diagnosis and treatment of incisional hernias develop after liver transplantation.
\end{abstract}

Keywords: Analyzis, incisional hernia, kidney transplantation 


\section{Giriş}

Ameliyatlardan sonra ortaya çıkabilecek ve hastanın yaşam kalitesini etkileyebilecek ciddi bir komplikasyon olan insizyonel herni, özellikle gelişen kozmetik sorunlar nedeniyle hastaları son derece rahatsız etmektedir [1].

Gelişmesi için en önemli predispozan faktörler; İleri yaş, erkek cinsiyet, vücut kitle indeksinin yüksek olması, Kronik Obstrüktif Akciğer Hastalığı, Diabetus Mellitus, albümin düşüklüğü, beslenme yetersizliği, yara yeri infeksiyonu, daha önceden geçirilmiş cerrahi, steroid kullanımı ve diğer immunosüpresif (m-TOR inhibitörleri) tedavilerdir [2,3].

İnsizyonel herni tanısında fizik muayeneye ek olarak radyolojik görüntüleme yöntemlerinden sıklıkla ultrasonografi ve bilgisayarlı tomografi kullanılmaktadır. Tedavisinde cerrahi (laparoskopik veya açık ) teknikler uygulanmaktadır [4].

$\mathrm{Bu}$ retrospektif çalışmanın amacı, böbrek nakli sonrası alıcı hastalarda gelişen insizyonel hernilerin değerlendirilmesidir.

\section{Materyal ve Metot}

\subsection{Hastalar}

Nisan 2014-Nisan 2019 tarihleri arasında İstanbul Medipol Üniversitesi Tıp Fakültesi Hastanesi Organ Nakli Bölümü'nde, böbrek nakli yapılan 150 hasta retrospektif olarak incelendi. İnsizyonel herni $7(\% 4,7)$ hastada saptandı. Bu hastaların demografik ve klinik özellikleri, predispozan faktörleri ve cerrahi sonuçları değerlendirildi.

Böbrek nakli yapılan tüm hastalarda sağ ya da sol inguinal bölgeye modifiye Gibson insizyonu kullanıldı. Ameliyat sonrası insizyonu kapatmak için ise kasların ( eksternal oblik, İnternal oblik ve transvers ) alt ve üst fasiaları ayrı ayrı kapatılacak şekilde yuvarlak Poliglaktin (Vicryl) No 1 ile devamlı dikişler kullanıldı.
Hastalara böbrek nakli sonrası standart immunsüpresif tedavi olarak ömür boyu kullanılacak Kalsinörin İnhibitörleri (Takrolimus veya Siklosporin ), ilk bir y1l kullanılacak Mikofenolat Mofetil ya da Mikofenolat Sodyum, ilk üç ay kullanılacak Prednizolon başlandı. Hastalar böbrek nakli sonrası taburculuklarından itibaren ilk ay haftada bir, ikinci ay onbeș günde bir, sonraki aylarda ise ayda bir kontrole geldi.

\subsection{Istatistiksel Analiz}

İstatistiksel analiz için SPSS 22.0 (Windows için SPSS, 2007, Chicago) kullanıldı. Normal dağılım gösteren sürekli değişkenler, ortalama \pm Standart sapma olarak verildi. Parametrik değişkenler için istatistiksel analiz Student's T-testi ile yapıldı. Niteliksel değişkenler yüzde olarak verildi ve kategorik değişkenler arasındaki korelasyon ki-kare testi ve Fisher's exact testi ile araştırıldı. İstatistiksel anlamlılık düzeyi $\mathrm{P}<0.05$ olarak tanımlandi.

\section{Bulgular}

Çalışmamız da böbrek nakli yapılan 150 hasta incelendi ve insizyonel herni $7(\% 4,7)$ hastada saptandı. Böbrek nakli sonrası insizyonel herni gelișen grupta yaş ortalaması $61 \pm 3,2$ yıl olup gelişmeyen gruba göre daha yüksekti $(p<0.05)$. Hastaların cinsiyeti açısından iki grup arasinda fark yoktu (p: 0.601). Yine insizyonel herni gelişen grupta vücut kitle indeksi $34.8 \pm 2,02$ kilogram/metrekare $\left(\mathrm{kg} / \mathrm{m}^{2}\right)$ olup gelişmeyen gruba göre daha yüksekti (p: 0.020).

Böbrek nakli sonrası insizyonel herni gelişen grupta Diabetus Mellitus ve yara yeri enfeksiyonu daha sik saptand 1 (sırasiyla p: 0.015 ve $\mathrm{p}<0.05$ ). Kronik obstrüktif akciğer hastalığı açısından iki grup arasında fark yoktu (p: 0.181). Tablo 1 de insizyonel herni için risk faktörleri karşılaştırılmıştır.

Table 1: İnsizyonel Herni İçin Risk Faktörlerinin Karşılaştırılması.

\begin{tabular}{|c|c|c|c|}
\hline & $\begin{array}{l}\text { İnsizyonel Herni Gelişmeyen Grup } \\
\qquad(\mathrm{n}=143)\end{array}$ & $\begin{array}{l}\text { İnsizyonel Herni Gelişen Grup } \\
\qquad(\mathrm{n}=7)\end{array}$ & $p$-value \\
\hline Yaş (yıl) & $38.6 \pm 11.3$ & $61 \pm 3.2$ & $<0.05$ \\
\hline Erkek / Kadın (n /\%) & $105(73.4 \%) / 38(26.6 \%)$ & $5(71.4 \%) / 2(28.6 \%)$ & 0.601 \\
\hline $\begin{array}{l}\text { Vücut Kitle İndeksi } \\
\text { (kilogram/metrekare) }\left(\mathrm{kg} / \mathrm{m}^{2}\right)\end{array}$ & $25.8 \pm 4.4$ & $34.8 \pm 2.02$ & 0.020 \\
\hline $\begin{array}{l}\text { Diabetes Mellitus } \\
\text { Yok/Var }(\mathrm{n} / \%)\end{array}$ & $108(\% 75.5) / 35(\% 24.5)$ & $2(\% 28.6) / 5(\% 71.4)$ & 0.015 \\
\hline $\begin{array}{l}\text { Kronik Obstrüktif Akciğer } \\
\text { Hastalığı Yok/Var (n/\%) }\end{array}$ & $128(\% 89.5) / 15(\% 10.5)$ & $5(\% 71.4) / 2(\% 71.4)$ & 0.181 \\
\hline $\begin{array}{l}\text { Yara Yeri Enfeksiyonu } \\
\text { Yok/Var }(\mathrm{n} / \%)(\mathrm{n} / \%)\end{array}$ & $143(\% 100) /-$ & $2(\% 28.6) / 5(\% 71.4)$ & $<0.05$ \\
\hline
\end{tabular}

Kontrollerde, fizik muayenesinde insizyonel herni saptanan hastalarda herniye ait defektin yapısını ve büyüklüğünü belirlemek için tüm batın bilgisayarlı tomografisi çekildi. 


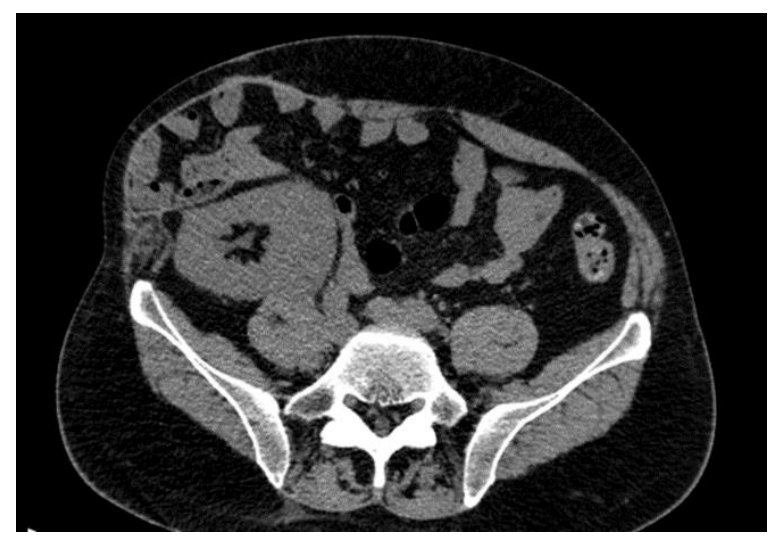

Şekil 1. Tüm batın bilgisayarlı tomografide nakil böbreği ve üst kısmında fitık kesesi görülmektedir .
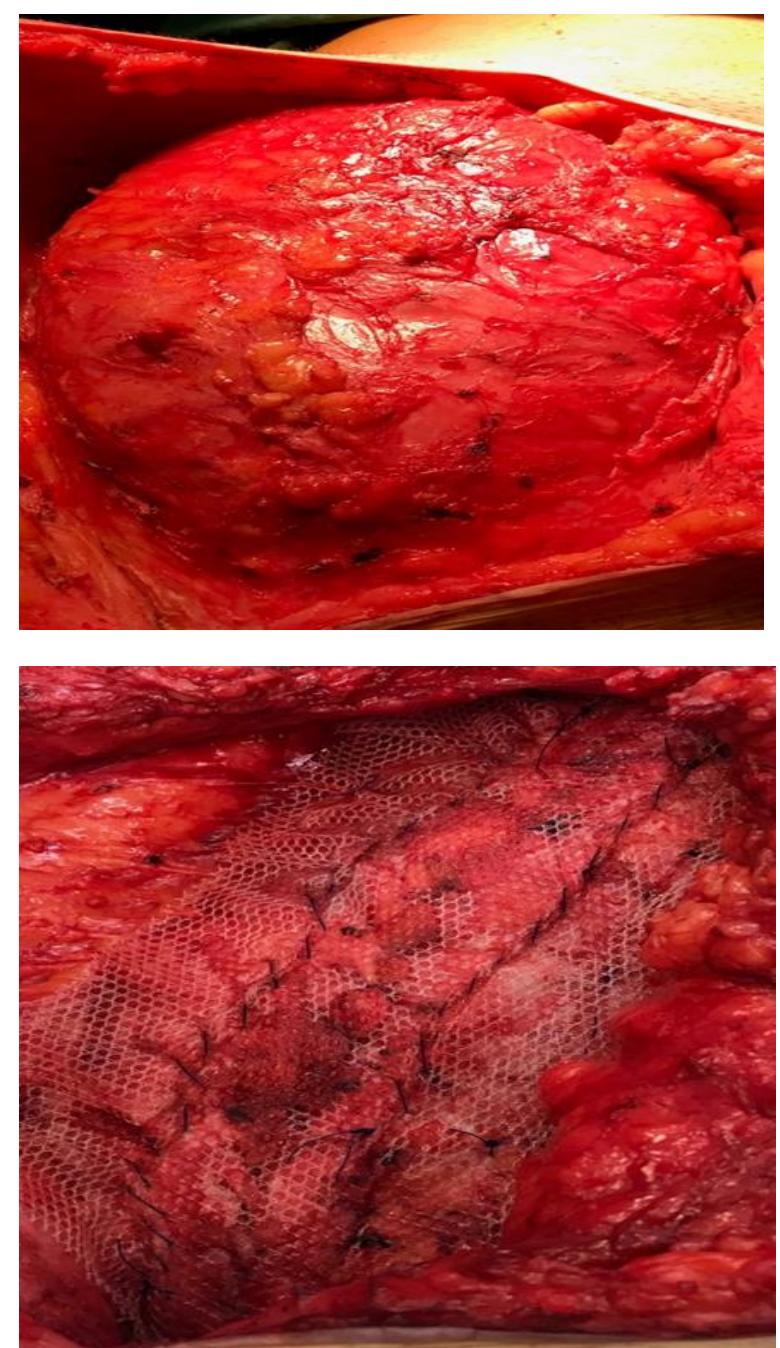

Şekil 2. Açık-onlay tekniği ile prolene mesh greft kullanılarak insizyonel herni tamiri görülmektedir.

İnsizyonel herni saptanan tüm hastalara açık- Onlay tekniği ile prolene mesh greft kullanılarak insizyonel herni tamiri yapıldı. Otuz dokuz (14-60) aylık takip süresinde herhangi bir komplikasyon ve insizyonel herni nüksü görülmedi.

\section{Tartışma}

İnsizyonel herni, tüm ameliyatlardan sonra ortaya çıkabilecek ve hastanın yaşam kalitesini bozabilecek ciddi bir komplikasyondur. İnsidansı karın cerrahisi geçiren hastalarda \%4-20 iken bu oran böbrek nakli sonrası \%1-5 arasında bildirilmektedir [5]. Çalışmamızda böbrek nakli yapılan $7(\% 4,7)$ hastada insizyonel herni saptand.

Yapılan birçok çalışmada böbrek nakli sonrası insizyonel herni gelişimi için ana predispozan faktörler arasında ileri yaş, erkek cinsiyet ve obesite bulunmaktadır [3,5].

Bizim çalışmamızda da böbrek nakli sonrası insizyonel herni gelişen hastaların yaş ortalaması ve vücut kitle indeksi daha yüksekti. Ancak hastaların cinsiyetinin herhangi bir etkisi saptanmadi.

Böbrek nakli sonrası insizyonel herni gelişimi için diğer risk faktörleri arasında alıcı hastalardaki Diabetus Mellitus ve kronik obstüriktif akciğer hastalığı, nakil sonrası gelişen yara yeri infeksiyonu, rejeksiyon nedeniyle bolus steroid tedavisi uygulanması ve immunsüpresif ajan olarak m-TOR inhibitörlerinin kullanılması yer almaktadır [5-8]. Çalışmamızda, Diabetus Mellitusu olan ve nakil sonrası yara yeri infeksiyonu gelişen hastalarda insizyonel herni daha s1k görülmüştür. Ancak kronik obstrüktif akciğer hastalığ ile insizyonel herni gelişimi arasında bir ilişkisi saptanmamıştır. Yine çalışmamızda insizyonel herni gelişen hastalar içerisinde akut rejeksiyon nedeniyle bolus streoid tedavisi alan ve immunsüpresif tedavi için m-TOR inhibitörü kullanılan hasta yoktu.

İnsizyonel herni tanısı için fizik muayenenin yanı sıra ultrasonografi ve tüm batın bilgisayarlı tomografisi gibi radyolojik görüntüleme yöntemleri kullanılmaktadır [9]. Çalışmamızda da fizik muayenesinde insizyonel herni saptanan hastalara herniye ait defektin yapısını ve büyüklüğünü belirlemek için tüm batın bilgisayarlı tomografisi çekildi.

İnsizyonel herni saptanan böbrek nakili alıcıları cerrahi olarak açık ya da laparoskopik teknikle ameliyat edilebilir. Hastalara ya primer tamir ya da çeşitli sentetik greftler ile tamir yapılır [4,10-12]. Çalışmamızda tüm hastalara açık olarak Onlay tekniği ile prolene mesh greft kullanılarak insizyonel herni tamiri yapıldı. İnsizyonel herni nedeniyle ameliyat edilen hastalarda nüks oranı açık olarak prolene mesh greft ile tamir edilenlerde \%2\%30 arasında bildirilmektedir [13-15]. Çalışmamızda otuz dokuz (14-60) aylık takip süresinde insizyonel herni nüksü ve herhangi bir komplikasyon görülmemiştir. Çalışmamızda bazı sınırlamalar mevcuttur. Bunlar çalışmanın retrospektif olması ve vaka sayısının az olmasidir.

\section{Sonuç}

Böbrek nakli sonrası gelişen insizyonel herni risk grubunda yaşlı, obez, diyabetik ve ameliyat sonrası yara yeri infeksiyonu gelişen hastalar vardı. Tartışma kısmında belirtilen sınırlamalara rağmen, böbrek nakli sonrası gelişen insizyonel hernilerin erken tanı ve tedavisi için özellikle bu hasta gruplarına dikkat edilmesi gerektiğini düşünüyoruz. 


\section{Referanslar}

1. Hidalgo, MP, Ferrero, EH, Ortiz, MA et al, Incisional hernia in patients at risk: can it be prevented? Hernia, 2011, 15, 371-375.

2. Smith, CT, Katz, MG, Foley, D et al, Incidence and risk factors of incisional hernia formation following abdominal organ transplantation, Surgical Endoscopy, 2015, 29, 398-404.

3.Yahchouchy-Chouillard, E, Aura, T, Picone, O et al, Incisional hernias Related risk factors, Digestive Surgery, 2003, 20, 3-9.

4. Forbes, SS, Eskicioglu, C, McLeod, RS et al, Metaanalysis of randomized controlled trials comparing open and laparoscopic ventral and incisional hernia repair with mesh, British Journal of Surgery, 2009, 96, 851-858.

5. Ooms, LS, Verhelst, J, Jeekel, J et al, Incidence, risk factors, and treatment of incisional hernia after kidney transplantation: an analysis of 1,564 consecutive patients, Surgery, 2016, 159, 1407-1411.

6. Dean, PG, Lund, WJ, Larson, TS et al, Wound-healing complications after kidney transplantation: a prospective, randomized comparison of sirolimus and tacrolimus, Transplantation, 2004, 77, 1555-1561.

7. Durinka, JB, Parsikia, A, Karipineni, F et al, Association between delayed graft function and incisional hernia after renal transplant, Experimental and Clinical Transplantation, 2017, 15, 27-33.

8. Valente, JF, Hricik, D, Weigel, K et al, Comparison of sirolimus vs mycophenolate mofetil on surgical complications and wound healing in adult kidney transplantation, American Journal of Transplantation 2003, 3, 1128-1134.

9. Moris, D, Bokos, J, Vailas, M et al, Renal paratransplant hernia revealed: a review of the literatüre, Hernia, 2017, 21, 363-367.

10. Petro, CC, Orenstein, SB, Criss, $\mathrm{CN}$ et al, Transversus abdominis muscle release for repair of complex incisional hernias in kidney transplant recipients, American Journal of Surgery, 2015, 210, 334 39.

11. Kieszek, R, Wszola, M, Domagała, P et al, Current trends in the treatment of incisional hernia in patients after kidney transplantation, Polski Merkuriusz Lekarski, 2010, 29, 50-53.

12. Mahdavi, R, Mehrabi, M, Incisional hernia after renal transplantation and its repair with propylene mesh, Urology Journal, 2004, 1, 259262.

13. Chang, EI, Galvez, MG, Padilla, BE et al, Ten-year retrospective analysis of incisional herniorrhaphy following renal transplantation, Archives of Surgery 2011, 146: 21-25.

14. Li, EN, Silverman, RP, Goldberg, NH, Incisional hernia repair in renal transplantation patients, Hernia, 2005, 9, 231-237.

15. Varga, M, Matia, I, Kucera, M et al. Polypropylene mesh repair of incisional hernia after kidney transplantation: single-center experience and review of the literatüre, Annals of Transplantation $2011,16,121-125$

http://edergi.cbu.edu.tr/ojs/index.php/cbusbed isimli yazarın CBU-SBED başlıklı eseri bu Creative Commons Alıntı-Gayriticari4.0 Uluslararası Lisansı ile lisanslanmıştır. 